\title{
Carbamazepine does not alter the intrinsic cardiac function in rats with epilepsy
}

\author{
Diego B. Colugnati ${ }^{1}$, Ricardo M. Arida², Roberta M. Cysneiros ${ }^{3}$, \\ Vera C. Terra ${ }^{4}$, Eliza Y.F. Sonoda ${ }^{1}$, Aline P. Pansani ${ }^{1}$, Carla A. Scorza ${ }^{1}$, \\ Esper A. Cavalheiro', Fulvio A. Scorza'
}

\begin{abstract}
Among the causes for sudden unexpected death (SUDEP) in epilepsy, the effects of antiepileptic drugs on the heart have been poorly explored. Based on this, the aim of our study was to evaluate the heart rate (in vivo and isolated ex vivo) and ventricular pressure (isolated ex vivo) of rats with and without epilepsy treated with carbamazepine. Four groups of adult, male Wistar rats (200-250 g) were studied: $[A]$ control rats $(n=8)$, received neither pilocarpine nor carbamazepine $[B]$ carbamazepine-treated rats $(n=8)$, received a daily dose of $120 \mathrm{mg} / \mathrm{Kg}$, i.p. of carbamazepine for two weeks; [C] rats with epilepsy that received just saline solution $(n=8) ;[D]$ rats with epilepsy that received a daily dose of $120 \mathrm{mg} /$ $\mathrm{Kg}$, i.p. of carbamazepine for two weeks $(n=8)$. Our results showed significant increase in heart rate in animals with epilepsy (with and without the use of carbamazepine) when compared to the control groups in vivo. In contrast, we did not find differences during isolated ex vivo experiments comparing animals with and without epilepsy and despite the use of carbamazepine. Our results suggest that, in isolation, carbamazepine may not be a potential risk factor for sudden unexpected death in epilepsy.
\end{abstract}

Key words: epilepsy, heart, SUDEP, seizure, antiepileptic drugs, carbamazepine.

Carbamazepina não altera o funcionamento cardíaco intrínseco em ratos com epilepsia

\section{RESUMO}

Entre as causas de morte súbita em epilepsia (SUDEPE), os efeitos das drogas antiepilépticas no coração têm sido pobremente explorados. Desta forma, o objetivo deste estudo foi avaliar a frequência cardíaca (in vivo e de forma isolada ex vivo) e a pressão ventricular (de forma isolada ex vivo) de ratos com e sem epilepsia tratados com carbamazepina. Quatro grupos de ratos Wistar machos adultos (peso 200 a $250 \mathrm{~g}$ ) foram estudados: $[A]$ ratos controle $(n=8)$, não receberam pilocarpina ou carbamazepina; $[B]$ ratos tratados com carbamazepina $(n=8)$, receberam dose diária de carbamazepina de $120 \mathrm{mg} / \mathrm{kg}$ intraperitoneal, durante duas semanas $(n=8) ;[C]$ ratos com epilepsia que receberam solução salina; [D] ratos com epilepsia que receberam dose diária de carbamazepina de 120 mg/ $\mathrm{kg}$ intraperitoneal durante duas semanas. Nossos resultados evidenciaram uma diferença estatisticamente significativa na média da freqüência cardíaca in vivo entre os animais com epilepsia (com e sem o uso de carbamazepina) quando comparados aos grupos controles in vivo. Em contraste, não observamos diferenças estatísticas nos experimentos ex vivo quando comparados os animais com ou sem epilepsia, a despeito do uso da carbamazepina. Nossos resultados sugerem que, de forma isolada, a carbamazepina pode não ser um fator de risco potencial para a ocorrência de morte súbita em epilepsia.

Palavras-chave: epilepsia, coração, SUPED, convulsão, drogas antiepilépticas, carbamazepina.

\section{Support}

FAPESP, CInAPCe-FAPESP and CNPq 
Epilepsy is the most common serious neurological condition ${ }^{1}$. Epidemiological studies suggest that between 70 and $80 \%$ of people developing epilepsy will go into remission, while the remaining patients continue to have seizures and are refractory to treatment with the currently available therapies ${ }^{2,3}$. The most common risk factors for epilepsy are cerebrovascular diseases, brain tumors, alcohol abuse, traumatic head injuries, cortical developmental malformations, genetic inheritance and central nervous system infections ${ }^{4}$. In resource-poor countries, endemic infections, such as malaria and neurocysticercosis seem to be major risk factors ${ }^{5}$.

Sudden unexpected death in epilepsy (SUDEP) is defined as sudden, unexpected, witnessed or unwitnessed, nontraumatic and nondrowning deaths in patients with epilepsy, with or without evidence of a seizure and excluding documented status epilepticus (SE), in which post mortem examination does not reveal a toxicological or anatomical cause of death ${ }^{6}$. Comparisons of estimates of incidence for SUDEP are difficult as different definitions of SUDEP have been used, not all patients have postmortem examination, case ascertainment methods and source populations is varied ${ }^{7}$. The incidence of SUDEP has been estimated as 3.5/1000 person-years in a lamotrigine clinical trial ${ }^{8}, 0.5-1.4 / 1000$ person-years in people with treated epilepsy ${ }^{9}, 5.9 / 1000$ person-years in outpatients with epilepsy at a tertiary referral centre ${ }^{10}, 9 / 1000$ person-years in candidates for epilepsy surgery and $0.35 / 1000$ personyears in a population-based study ${ }^{11}$. The National General Practice Study of Epilepsy (NGPSE), a communitybased study in the United Kingdom has seen the first case of SUDEP after 11,000 person-years of follow-up ${ }^{12}$ and the results of the Medical Research Council Antiepileptic Drug Withdrawal Study showed that SUDEP among patients with epilepsy in remission is a rare event ${ }^{13}$. Information concerning risk factors for SUDEP is conflicting, but potential risk factors include: age ${ }^{11}$, early onset of epilepsy ${ }^{14}$, duration of epilepsy ${ }^{15}$, uncontrolled seizures, mainly in the temporal lobe epilepsy ${ }^{15,16}$, seizure frequen$\mathrm{cy}^{15-17}$ seizure type $\mathrm{e}^{15-18}$, winter temperatures ${ }^{19}$ and antiepileptic drugs therapy (AEDs) ${ }^{14,15,20}$. The impact of AEDs on the risk of SUDEP has been evaluated from different angles: some studies have suggested more frequent AEDs changes or suboptimal AEDs dosage at the time of death in SUDEP patients ${ }^{14,18,21}$, however, some studies failed to confirm these findings or detect a difference in compliance to AEDs therapy between SUDEP and non-SUDEP patients $^{21-23}$. Moreover, the potential arrythmogenic side effect of carbamazepine has also been suspected to increase the risk of SUDEP ${ }^{16,21,24}$, mainly when associated with plasma levels above $40 \mu \mathrm{mol} / \mathrm{l}^{21,23,24}$, but this issue also remains controversial ${ }^{14,15,21,23}$

Considering the potential importance of carbam- azepine (CBZ) on cardiovascular function that could culminate in SUDEP, the aim of our study was to analyze the heart rate and the ventricular pressure in vivo and isolated ex vivo of rats with epilepsy and treated with CBZ.

\section{METHOD}

\section{Animals}

Four groups of adult, male Wistar rats (200-250 g) were studied: $[A]$ control rats $(n=8)$, received neither pilocarpine nor CBZ; [B] CBZ-treated rats $(\mathrm{n}=8)$, received just a dose of $40 \mathrm{mg} / \mathrm{Kg}$ three times day, i.p. of CBZ for two weeks; $[\mathrm{C}]$ rats with epilepsy that received just saline solution $(\mathrm{n}=8) ;[\mathrm{D}]$ rats with epilepsy that received a dose of $40 \mathrm{mg} / \mathrm{Kg}$ three times day, i.p. of CBZ for two weeks ( $n=8)$. It is important to note that the efficacy of CBZ dose $(120 \mathrm{mg} / \mathrm{kg})$ used in the present study was determined in a previous study evaluated by our research group $^{25}$. All animals used in our study were housed under standard controlled conditions (7:00 AM/7:00 P.M. light/ dark cycle; $20-22^{\circ} \mathrm{C} ; 45-55 \%$ humidity) with food and water ad libitum. All animals were treated according to protocols for animal care established by ethical committee from Federal University of São Paulo, and all efforts were made to minimize animal suffering. The project was approved by the local ethical committee.

\section{Induction of status epilepticus (SE)}

Adult male Wistar rats (250-300g) were given a subcutaneous (s.c.) injection of methylscopolamine $(1 \mathrm{mg} / \mathrm{kg}$; Sigma, St. Louis, MO) followed 30 minutes later by an i.p. injection of pilocarpine hydrochloride (350 mg $/ \mathrm{kg}$; Sigma, St. Louis, MO) to induce SE. Seizure activity was monitored considering animal behaviour and terminated with an i.p. injection of diazepam (10 mg/kg; Roche, Brazil) after 4 hr of convulsive SE. Only rats that displayed continuous, convulsive seizure activity for for $4 \mathrm{hr}$ after pilocarpine treatment and without significant hypoxia were included in this study ${ }^{25}$. Sixty days after SE induction, all animals were fully recovered from status epilepticus and were selected for treatment with CBZ randomly. The rats treated with CBZ (Sigma, St. Louis, MO) started to receive a daily dose $(120 \mathrm{mg} / \mathrm{Kg}$, i.p.) during two weeks.

\section{Heart rate device}

To mesure the HR we used a HR apparatus developed in our laboratory, which allowed us to monitor heart electrical activity without inserting fixed skin electrodes $(\text { Fig } 1)^{26}$. This characteristic is very important because any contact to the body of the animal can stress it and consequently alter the $\mathrm{HR}^{27}$. In brief, the animals were placed inside the box, which was previously cleaned with a solution of $1 \mathrm{mM}$ of acetic acid. The procedure with acid acetic (followed by drying with paper towel) is fundamental 


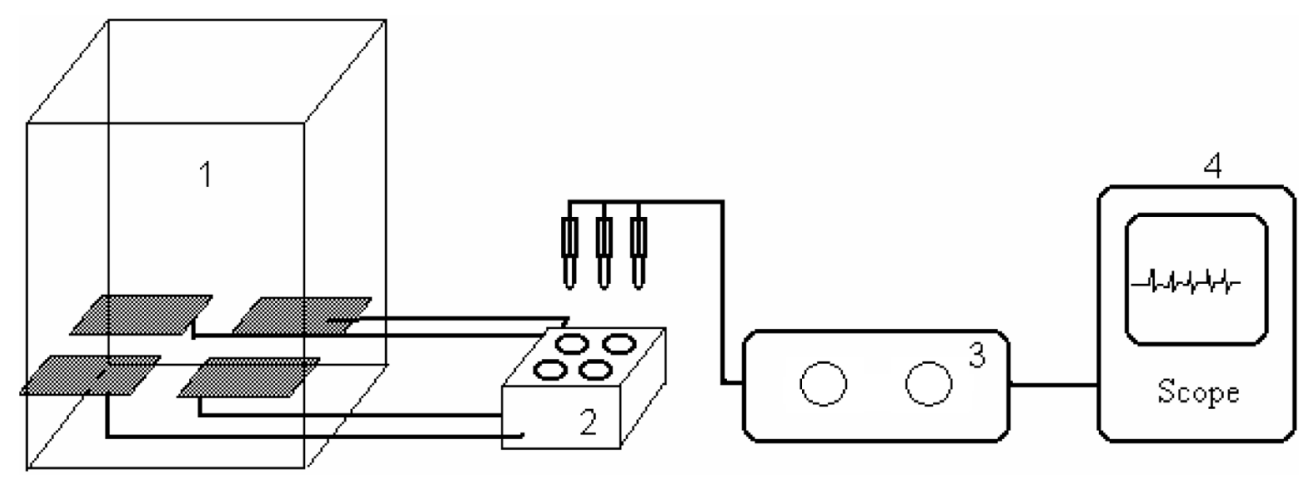

Fig 1. Heart rate apparatus: [1] acrylic box with electrodes; [2] switch of the electrodes; [3] amplifier; [4] scope.

(9)

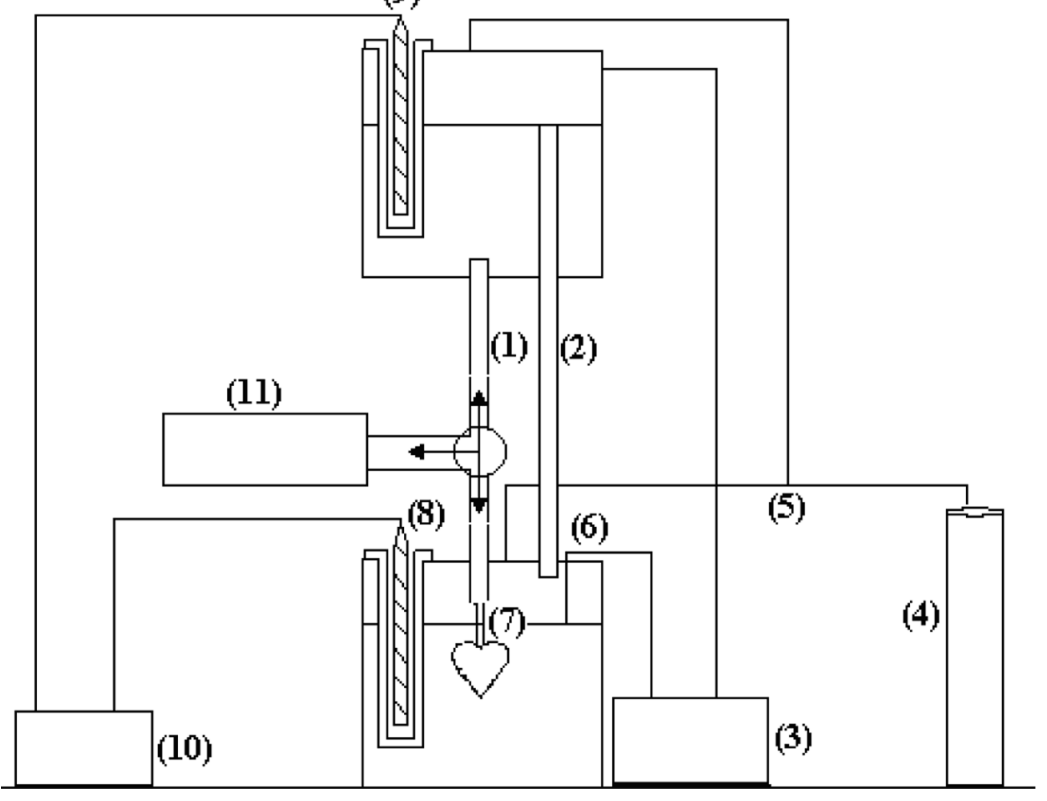

Fig 2. Schematic figure of the experimental camera. To the center, we have the inferior and superior compartment, interlinked for a perfusion hose [1] and a lateral hose [2], [3] peristaltic pump, [4] carbogenic solution, [5] and [6] hoses for carbogenic solution conduction and circulation of the solution respectively, [7] stem for the aorta, [8] and [9] resistances, [10] power supply [11] pressure transducer. to eliminate coming scents of the previous animal. Following animal's habituation (approximately 10 minutes) we started the commutation of the plus's cables, with the objective to obtain a sign that makes possible the recognition of the R-R interval of each animal. This procedure is very simple, taking approximately 15 minutes.

\section{Isolated ex vivo procedures}

Solutions - To wash the hearts, we used the KrebsHenseleit solution ( $\mathrm{KH}$ ) composed by (in $\mathrm{mM}$ ): sodium chloride 126.4; potassium chloride 4.6; $\mathrm{KH}_{2} \mathrm{PO}_{4}$ 1.2; magnesium sulfate 1.2; sodium bicarbonate 13.6; calcium chloride 1.5; GLUCOSE 11.11, pH 7.4 to $36^{\circ} \mathrm{C}$, saturated with $95 \%$ of $\mathrm{O}_{2}, 5 \%$ of $\mathrm{CO}_{2}$.

Experimental camera - The experimental camera used in our study was developed in our lab (Fig 2) and allows the recording of the experiments in a well controlled way. The camera's principles are:
[A] The isolated heart is maintained under perfusion with physiologic solution in a retrograde way for the aorta (Preparation of Langendorf);

[B] The temperature of the solution is maintained $\left(36^{\circ} \mathrm{C}\right)$;

[C] The solution is bubbled continuously with a carbonic solution $\left(95 \% \mathrm{O}_{2}+5 \% \mathrm{CO}_{2}\right)$;

[D] The pressure developed by the left ventricle during the systole is monitored.

Ventricular pressure and heart rate - As shown in Fig 3, a pressure transducer (TP) is coupled at a derivation of the bath that takes the perfusion solution to the heart in a close point to the stem. The pressure measured by the transducer during the contractions is amplified and registered in a digital oscilloscope (Tektronix, Inc, USA) with interface for printer. With this, we could characterize the mechanical activity of the hearts: the spontaneous heart frequency $(\mathrm{Hz})$ and converted later for bpm, 


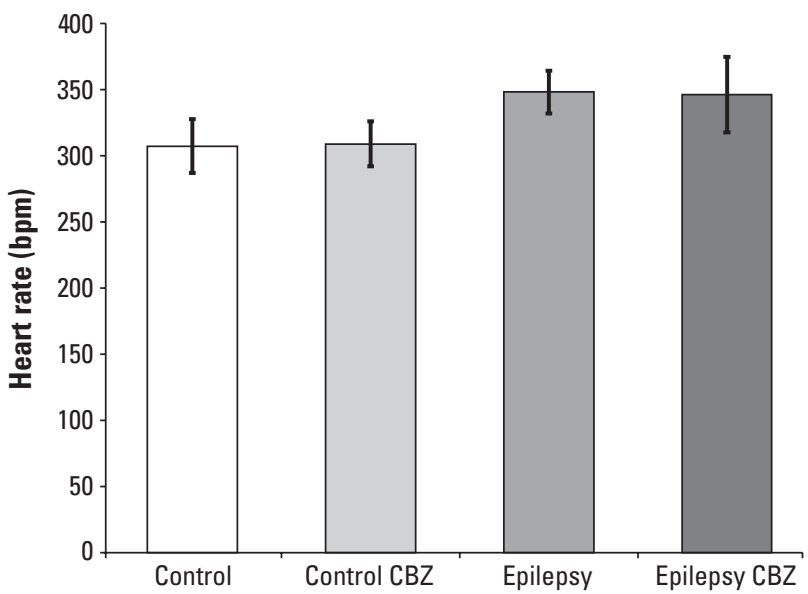

Fig 3. Means and standard deviation of the heart rates of all groups obtained in vivo situation.

and the maximum pressure developed by the left ventricle (mmHg).

Preparation of the sample and experimental protocol - All animals were killed with a guillotine 74 days after the pilocarpine injection. The hearts was removed and submerged in $\mathrm{KH}$ solution to clean its cameras, arteries and veins. After this, the aorta was canulated and then mounted in the experimental camera. The heart was retrograde perfused with $\mathrm{KH}$ (until to stabilize), that typically happened between 15 and 30 minutes. The registration obtained in the oscilloscope was printed and analyzed later.

\section{Statistical analysis}

To determine statistical differences between groups, we used a bifactorial variance analysis and the Turkey's post-test. For each parameter (heart frequency and pressure) we considered statistical differences among the groups with $\mathrm{p}<0.05$.

\section{RESULTS}

Pilocarpine treatment sequentially induced the following behavioral changes: akinesia, facial automatisms, and limbic seizures consisting of forelimb clonus with rearing, salivation, and masticatory jaw movements and falling. This type of behavior built-up progressively into motor limbic seizures that recurred repeatedly and rapidly developed into SE. After SE, animals were comatose or unresponsive to their environment and akinetic. Behavior returned to normal over a 3- to 5-day period. Spontaneous recurrent seizures in rats with epilepsy observed during the chronic period of the pilocarpine model of epilepsy were characterized by facial automatisms, forelimb clonus, rearing, loss of postural control and generalized clonic seizures lasting 40-60s. CBZ was introduced six day after pilocarpine injection and had a marked suppres-
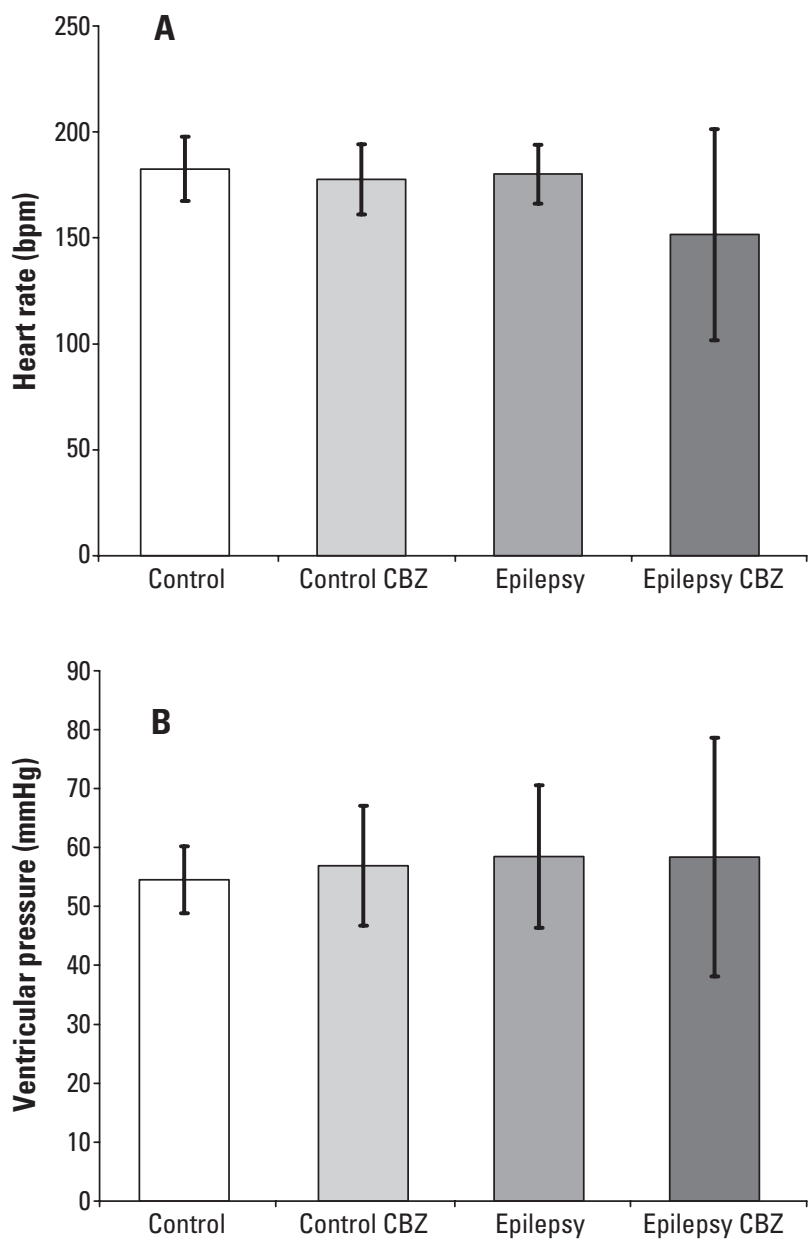

Fig 4. Means and standard deviation of the heart rates and ventricular pressures of all groups obtained in vitro situation.

sant action on spontaneous seizures. Seizure frequency during baseline period was 1.96 seizure episodes per day per animal, 0.097 during CBZ treatment period and 2.09 during post-treatment period ( $\mathrm{p}>0.05)$.

In the next step, the heart parameters (in vivo and isolated ex vivo procedures) were evaluated. Our results showed that HR in vivo (under influence of the autonomic nervous system) of animals with epilepsy treated with CBZ (346 $\pm 28 \mathrm{bpm})$ and without CBZ treatment $(348 \pm 16$ $\mathrm{bpm})$ were higher when compared with rats of the control groups (with CBZ: $307 \pm 20 \mathrm{bpm}$; and without CBZ: $309 \pm 17$ bpm; $>0.05$ ) (Fig 3). On the other hand, in the isolated ex vivo experiments, no significant differences in mean HR of rats with epilepsy treated with CBZ $(151 \pm 50$ $\mathrm{bpm})$, without CBZ treatment $(180 \pm 14 \mathrm{bpm})$ and control groups (with CBZ: $182 \pm 15 \mathrm{bpm}$; and without CBZ: $177 \pm 16 \mathrm{bpm}$ ) were observed (Fig 4A). In the same way, a similar result was observed for the parameter of ventricular pressure, i.e., rats with epilepsy and treated with CBZ $(58 \pm 20 \mathrm{mmHg})$, without CBZ treatment $(58 \pm 12 \mathrm{mmHg})$ 
and control groups (with CBZ: $54 \pm 5 \mathrm{mmHg}$; and without CBZ: $56 \pm 10 \mathrm{mmHg}$ ) did not show statistical differences (Fig 4B).

\section{DISCUSSION}

The present study evaluated the heart rate (in vivo and isolated $e x v i v o$ ) and ventricular pressure (isolated $e x$ vivo) of rats with and without epilepsy treated with CBZ. Our results showed that rats with epilepsy had a significant increase in HR when compared to controls, probable secondary to functional autonomic changes that occur in cerebral function ${ }^{28}$. Although, CBZ did not increase in a maintained way significantly the HR of rats studied during in vivo situation and did not alter the ventricular pressure during isolated ex vivo situation as well.

As we know, SUDEP is responsible for $7.5 \%$ to $17 \%$ of all deaths in epilepsy and has an incidence among adults between 1:500 and 1:1,000 5 , and AEDs therapy is one of the many risk factors suggested for SUDEP. Although several studies suggested increase risk of SUDEP with increasing number of AEDs used ${ }^{7,29}$, a very few studies have made attempts to verify if there is an association between specific AEDs, cardiovascular abnormalities and hence SUDEP. Furthermore, it has been shown that CBZ is able to affect the conduction system of the heart and the autonomic nervous system as well ${ }^{29-31}$. Although our study did not find $H R$ and ventricular pressure differences with CBZ administration during in vivo and isolated ex vivo situation, a number of arguments might be put forward. To do so, interesting studies developed by Timmings ${ }^{32,33}$ showed that CBZ was disproportionately represented in patients suffering SUDEP. Thus, the authors demonstrated that 11 of the 14 SUDEP (79\%) patients were taking CBZ at the time of death. Moreover, the results also indicated that one patient was not taking any drug therapy, and died during his first seizure, reducing the number of evaluable 'drug usage' patients to 13 , and increasing the proportion taking $\mathrm{CBZ}$ at the time of death to $85 \%$. As possible mechanisms, Timmings ${ }^{33}$ suggests that CBZ induced lengthening of the ECG Q-T interval combined with a mild pro-arrhythmic effect of epileptic seizure discharges, and consequent transient cardiac instability leading to arrhythmic death ${ }^{32,33}$. It is important to note that in these studies, no attempts were made to control and associate SUDEP cases for other recognized potential SUDEP risk factors, such as duration of epilepsy, seizure frequency, age, polytherapy and winter temperatures ${ }^{7,19,34}$. In parallel, Nilsson and colleagues ${ }^{15}$ demonstrated that high CBZ plasma levels (above $40 \mu \mathrm{mol} / \mathrm{l}$ ) was a risk factor for SUDEP, point to the risks associated with unstable severe epilepsy. Although this result was not confirmed in the U.S. study ${ }^{15}$, we have to be in mind that CBZ is metabolized by hepatic P450 isoenzyme CYP 3A and when drugs that inhibit CYP 3A are administered together, plasma levels of parent drug may increase, thus leading to further cardiovascular abnormalities (lengthening of the QT interval) and increasing the risk of sudden death ${ }^{35}$.

In contrast to $\mathrm{CBZ}$ as potential risk factor to SUDEP, there is a growing body of clinical studies in agreement with our experimental results suggesting that CBZ, at therapeutic levels, has no or minimal effects on the heart conduction system, supporting its safe use in the absence of cardiac disease $\mathrm{e}^{1,31}$. In fact, three larger controlled studies described that the use of CBZ was not increased in SUDEP cases when compared with control subjects ${ }^{14,15,18}$. Following this, it is reasonable to think that CBZ may not precipitate prolongation of the QT interval into SUDEP, but patients are still at risk for cardiovascular alterations for other reasons such as co-medication with other drugs, electrolyte imbalance and hepatic or renal impairment.

SUDEP is usually unwitnessed and the majority of people dying with SUDEP are found in or near the bed ${ }^{18}$, presumably during sleep. Quite interesting, Hennessy and colleagues ${ }^{36}$ described that abrupt withdrawal of CBZ leads to enhanced sympathetic activity in sleep as evidenced by changes in heart hate variability, suggesting that increased sympathetic activity in the setting of seizure-induced hypoxia could predispose to SUDEP. Although our study has only considered the heart rate parameters during CBZ treatment and we did not find any cardiovascular dysfunctions in our set of experiments, this question should not be neglected. As we know, hyponatremia is a usual electrolyte disorder and is defined as serum sodium $<135 \mathrm{mmol}$ per liter ${ }^{3}$. Because of the fact that sodium is the dominant electrolyte of the extracellular fluid and the primary determinant of serum osmolality, the disturbances of sodium homeostasis can lead to pathologic alterations in cell functions ${ }^{37,38}$. It has been determined that diuretics are the most common drugs which induce hyponatremia, but there are a few case reports in literature in which hyponatremia is induced by another therapy, including CBZ treatment ${ }^{39}$. Taken together, this electrolytic anomaly can derive in secondary cardiovascular effects, in so outstanding occasions, as to produce the phenomenon denominated SUDEP.

According to the current knowledge, improved seizure control seems to be one of the most important measures to prevent SUDEP; however, AEDs (mainly polytherapy management) are equally dangerous regarding SUDEP $^{31}$. Finally, further studies are needed to gain a better understanding of the role of $\mathrm{CBZ}$ as a potential risk factor to SUDEP, but in the mean time caution with CBZ continuous to be prudent and necessary.

ACKNOWLEDGMENTS - The authors would like to thank Sérgio Gomes da Silva for his help with technical procedures. 


\section{REFERENCES}

1. Sander JW. The epidemiology of epilepsy revisited. Curr Opin Neurol 2003; 16:165-170.

2. Kwan P, Sander JW. The natural history of epilepsy: an epidemiological view. J Neurol Neurosurg Psychiatry 2004;75:1376-1381.

3. Sander JW. Some aspects of prognosis in the epilepsies: a review. Epilepsia 1993;34:1007-1016.

4. Halatchev VN. Epidemiology of epilepsy: recent achievements and future. Folia Medica (Plovdiv) 2000;42:17-22.

5. Duncan JS, Sander JW, Sisodiya SM, Walker MC. Adult epilepsy. Lancet 2006; 367:1087-1100

6. Nashef L. Sudden unexpected death in epilepsy: terminology and definitions. Epilepsia 1997;38 (Suppl):S6-S8

7. Tomson T, Walczak T, Sillanpaa M, Sander JW. Sudden unexpected death in epilepsy: a review of incidence and risk factors. Epilepsia 2005;46(Suppl 11):S54-S61.

8. Leestma JE, Annegers JF, Brodie MJ, et al. Sudden unexplained death in epilepsy: observations from a large clinical development program. Epilepsia 1997:38:47-55.

9. Tennis P, Cole TB, Annegers JF, Leestma JE, McNutt M, Rajput A. Cohort study of incidence of sudden unexplained death in persons with seizure disorder treated with antiepileptic drugs in Saskatchewan, Canada. Epilepsia 1995;16:29-36.

10. Nashef L, Fish DR, Sander JW, Shorvon SD. Incidence of sudden unexpected death in an adult outpatient cohort with epilepsy at a tertiary referral centre. J Neurol Neurosurg Psychiatry 1995;58:462-464.

11. Ficker DM, So EL, Shen WK, et al. Population-based study of the incidence of sudden unexplained death in epilepsy. Neurology 1998:515:1270-1274.

12. Lhatoo SD, Sander JW. The epidemiology of epilepsy and learning disability. Epilepsia 2001;42(Suppl 1):S6-S9.

13. Medical Research Council Antiepileptic Drug Withdrawal Study Group. Randomised study of antiepileptic drug withdrawal in patients in remission. Lancet 1991;337:1175-1180.

14. Nilsson L, Farahmand BY, Persson PG, Thiblin I, Tomson T. Risk factors for sudden unexpected death in epilepsy: a case-control study. Lancet 1999;53: 888-893.

15. Walczak TS, Leppik IE, D'Amelio M, et al. Incidence and risk factors in sudden unexpected death in epilepsy: a prospective cohort study. Neurology 2001:56:519-525.

16. Langan Y, Nashef L, Sander JW. Case-control study of SUDEP. Neurology 2005; 64:1131-1133.

17. Sperling MR, Feldman H, Kinman J, Liporace JD, O'Connor MJ. Seizure control and mortality in epilepsy. Ann Neurol 1999:46:45-50.

18. Kloster R, Engelskjon T. Sudden unexpected death in epilepsy (SUDEP): a clinical perspective and a search for risk factors. J Neurol Neurosurg Psychiatry 1999;67:439-444

19. Scorza FA, Albuquerque M, Arida RM, Cavalheiro EA. Sudden unexpected death in epilepsy: are winter temperatures a new potential risk factor? Epilepsy Behav 2007;10:509-510.
20. Nilsson L, Bergman U, Diwan V, Farahmand BY, Persson PG., Tomson T. Antiepileptic drug therapy and its management in sudden unexpected death in epilepsy: a case-control study. Epilepsia 2007;42:667-673.

21. Ryvlin P, Montavont A, Kahane P. Sudden unexpected death in epilepsy: from mechanisms to prevention. Curr Opin Neurol 2006;19:194-199.

22. Opeskin K, Berkovic SF. Risk factors for sudden unexpected death in epilepsy: a controlled prospective study based on coroners cases. Seizure 2003;12: 456-464.

23. Shields LB, Hunsaker DM, Hunsaker JC 3rd, Parker JC Jr. Sudden unexpected death in epilepsy: neuropathologic findings. Am J Forensic Med Pathol 2002:23:307-314.

24. Opeskin K, Burke MP, Cordner SM, Berkovic SF. Comparison of antiepileptic drug levels in sudden unexpected deaths in epilepsy with deaths from other causes. Epilepsia 1999;40:1795-1798.

25. Leite JP, Cavalheiro EA. Effects of conventional antiepileptic drugs in a model of spontaneous recurrent seizures in rats. Epilepsy Res 1995;20:93 104

26. Colugnati DB, Gomes PA, Arida RM, et al. Analysis of cardiac parameters in animals with epilepsy: possible cause of sudden death? Arq Neuropsiquiatr 2005;63:1035-1041.

27. Balcombe JP, Barnard ND, Sandusky C. Laboratory routines cause animal stress. Contemp Top Lab Anim Sci 2004:43:42-51.

28. Koseoglu E, Kucuk S, Arman F, Ersoy AO. Factors that affect interictal cardiovascular autonomic dysfunction in temporal lobe epilepsy: role of hippocampal sclerosis. Epilepsy Behav 2009;16:617-621.

29. Bell GS, Sander JW. Sudden unexpected death in epilepsy. Risk factors, possible mechanisms and prevention: a reappraisal. Acta Neurol Taiwan 2006; 15:72-83.

30. Isojärvi J, Ansakorpi H, Suominen K, Tolonen U, Repo M, Myllylä W. Interic tal cardiovascular autonomic responses in patients with epilepsy. Epilepsia 1998;39:420-426.

31. Stollberger C, Finsterer J. Cardiorespiratory findings in sudden unexplained/ unexpected death in epilepsy (SUDEP). Epilepsy Res 2004;59:51-60.

32. Timmings PL. Sudden unexpected death in epilepsy: is carbamazepine implicated? Seizure 1998;7:289-291.

33. Timmings PL. Sudden unexpected death in epilepsy: a local audit. Seizure 1993:2:287-290

34. Scorza FA, Colugnati DB, Pansani AP, Sonoda EY, Arida RM, Cavalheiro EA Preventing tomorrow's sudden cardiac death in epilepsy today: what should physicians know about this? Clinics 2008;63:389-394.

35. Kwon S, Lee $S$, Hyun M, et al. The potential for QT prolongation by antiepileptic drugs in children. Pediatr Neurol 2004;30:99-101.

36. Hennessy MJ, Tighe MG, Binnie CD, Nashef L. Sudden withdrawal of carbamazepine increases cardiac sympathetic activity in sleep. Neurology 2001;57: 1650-1654.

37. Adler SM, Verbali JG. Disorders of body water homeostasis in critical illness. Endocrinol Metab Clin North Am 2006:35:873-894.

38. Adrogué HJ, Madias NE. Hypernatremia. N Engl J Med 2000;342:1493-1499.

39. Dong X, Leppik IE, White J, Rarick J. Hyponatremia from oxcarbazepine and carbamazepine. Neurology 2005;65:1976-1978. 